Mal J Nutr 25(2): 199-207, 2019

\title{
Overweight and obesity among Orang Asli adults in Krau Wildlife Reserve, Pahang: a four-year follow-up study
}

\author{
Chua Ee Yin, Zalilah Mohd Shariff*, Norhasmah Sulaiman \& Geeta Appannah \\ Department of Nutrition and Dietetics, Faculty of Medicine and Health Sciences, \\ Universiti Putra Malaysia, Selangor, Malaysia
}

\begin{abstract}
Introduction: Obesity and excess weight gain in adults are linked to an increased risk of cardiometabolic abnormalities. The changing lifestyle experienced by the Orang Asli predisposes the population to the risk of obesity and non-communicable diseases. This study aimed to describe the prevalence of overweight and obesity as well as body-weight change over a period of four years among Orang Asli adults. Methods: Data were collected from Orang Asli adults aged $\geq 18$ years, who were enrolled in the 2011-2012 and 2015-2016 surveys, and who were residing within the Krau Wildlife Reserve. Weight and height of the adults $\left(N_{2011-2012}=828 ; N_{2015}\right.$ $\left.{ }_{2016}=662\right)$ were measured at both time points. Follow-up data were available for 378 adults (male:113; female:265). Results: The prevalence of overweight and obesity were $18.8 \%$ and $7.4 \%$ in $2011-2012$ and $26.1 \%$ and $9.5 \%$ in $2015-2016$. In the follow-up group, significant differences in body weight and body mass index (BMI) were observed in men and women, respectively. More than one-third $(35.5 \%)$ of the adults had weight gain of more than $5.0 \%$. The increasing percentage of body weight change was associated with being female, younger age, more years of schooling and reduced household income. Conclusion: Obesity is a growing health problem in the Orang Asli adult population. Weight gain was associated with socioeconomic indicators and it was more prominent in women. Effective strategies are needed to address the increasing prevalence of overweight and obesity in this population to further reduce adverse health outcomes.
\end{abstract}

Keywords: Overweight and obesity, weight gain, Orang Asli adults

\section{INTRODUCTION}

The global age-standardised mean body mass index (BMI) increased between 1975 and 2014 in both men (from 21.7 to 24.2) and women (from 22.1 to 24.4) (NCD-RisC, 2016). Over these four decades, the age-standardised prevalence of obesity increased from $3.2 \%$ to $10.8 \%$ in men and from $6.4 \%$ to $14.9 \%$ in women. Meanwhile, agestandardised global prevalence of underweight decreased from $13.8 \%$ to $8.8 \%$ in men and from $14.6 \%$ to $9.7 \%$ in women. Obesity is a global health problem. Likewise, the 2015 Global Burden of Disease study (GBD 2015 Obesity Collaborators, 2017) reported a rapid rise in the prevalence and disease burden of elevated BMI.

*Corresponding author: Prof. Dr. Zalilah Mohd Shariff

Professor (Community Nutrition), Department of Nutrition and Dietetics

Faculty of Medicine and Health Sciences, Universiti Putra Malaysia, 43400 Serdang Selangor, Malaysia

Tel: 603 89472472; Fax: 603 89426769; Email: zalilahms@upm.edu.my

doi: https://doi.org/10.31246/mjn-2018-0169 
Weight gain had a negative impact on cardiometabolic risk factors in metabolically healthy $(\mathrm{MH})$ adults, irrespective of their weight status (Cui et al., 2015). It is associated with increased systolic and diastolic blood pressure, triglycerides and blood glucose in both obese and normal weight adults. A cohort study showed that $\mathrm{MH}$ obese and normal weight adults with weight gain of $\geq 10.0 \%$ and $\geq 15.0 \%$ of body weight, respectively, were more likely to have developed metabolic complications compared to those who did not gain weight (Espinosa De Ycaza, Donegan \& Jensen, 2018).

Previous studies have highlighted the double burden of malnutrition in Orang Asli population (Wong et al., 2015; Geik, Sedek \& Awang, 2016; Siti Fatihah et al., 2018). Although undernutrition is still prevalent in children, overweight and obesity are increasing in adults. Similar to the non-indigenous population in Malaysia, the changing disease patterns are towards non-communicable diseases in the adult Orang Asli population (Phipps et al., 2015; Chua et al., 2017). This may reflect the changes in body weight status driven by changes in their dietary and lifestyle behaviours.

Monitoring the change in body weight of indigenous peoples, particularly adults, is a challenge as the population is often mobile and difficult-to-reach. This study aimed to assess body weight status of Orang Asli adults, specifically their BMI and change in body weight, over a period of four years. The associations between percentage change in body weight and socioeconomic variables were also examined.

\section{MATERIALS AND METHODS}

During the period 2011-2012, a survey was conducted among Orang Asli of the Jah Hut sub-tribe who were living seven villages within the Krau Wildlife Reserve in Peninsular Malaysia. Out of 467 households within the study location, 465 households were visited and 1368 adults aged $\geq 18$ years were identified based on interviews with household heads. Among these adults, 34 pregnant women and 12 bedridden adults were excluded from the study. A total of 914 adults were located and approached but only 828 adults gave consent to participate. All the eligible adults were measured for weight and height and interviewed on a range of sociodemographic characteristics.

In 2015-2016, another survey was conducted in the same seven Orang Asli villages and 446 out of 458 households were visited. Based on household interviews, there were 1,596 adults aged $\geq 18$ years who were available within the study location. A total of 32 adults, comprising 18 pregnant women and 14 bedridden adults, were excluded from the study. Out of 1,564 adults, 986 were identified and invited to participate in the study. Of the 662 adults who agreed to participate and completed the interview and anthropometric measurements, 378 adults were identified as the cohort of 2011-2012 survey and 284 adults were newly recruited participants. Reasons for attrition included refusal, death of respondents and households that had moved from the location.

The BMI of each participant was derived from weight and height measurements. In the follow-up group, the change in body weight $(\mathrm{kg})$ and percentage $(\%)$ body weight change were calculated. The latter was categorised into five groups: (i) weight loss (weight loss $>5.0 \%$ ), (ii) stable weight (weight loss or gain $\leq 5.0 \%$ ), (iii) slight weight gain (weight gain $>5.0 \%$ and up to $10.0 \%$ ), (iv) moderate weight gain (weight gain $>10.0 \%$ and up to $20.0 \%$ ) and (v) excess weight gain (weight gain $>20.0 \%$ ) (Yiengprugsawan et al., 2017).

Statistical analyses were performed using IBM SPSS Statistics 21.0 (IBM 
Corporation, New York, USA). All variables are presented as mean, standard deviation, and frequency. Paired- $t$ test assessed the differences in anthropometric measures of the followup group between the year 2011-2012 and 2015-2016. Pearson's correlation and Chi-square tests were used to assess the associations of continuous and categorical variables, respectively. The level of significance was set at $p<0.05$.

\section{Ethical approval}

The Medical Research Ethics Committee of the Faculty of Medicine and Health Sciences, Universiti Putra Malaysia approved the study protocol. Permission to conduct this study was obtained from the Malaysia Department of Orang Asli Development (JAKOA) and the Department of Wildlife and National Parks of Peninsular Malaysia (PERHILITAN).

\section{RESULTS}

More than one-fourth (26.2\%) and onethird (35.6\%) of Orang Asli adults were either overweight or obese, in 2011-2012 and 2015-2016, respectively (Table 1). The proportion of overweight and obesity was higher in women than men at each time point. About $10.0 \%$ of the study population $(11.1 \%$ in 2011-2012 and $9.4 \%$ in $2015-2016)$ were underweight. Between 2011-2012 and 2015-2016, the mean body weight $(\mathrm{kg})$ increased slightly for men (from 59.3 to 61.1) and women (from 51.4 to 52.8). Corresponding to these changes, the mean BMI increased from 23.2 to 23.9 in men and from 23.3 to 23.8 in women. The changes in body weight and BMI in both men and women were statistically significant.

All the obese men were found to remain in the same BMI category over the period of four years. Meanwhile, changes across the BMI distribution were revealed among $25.7 \%$ of the follow-up group, where $18 \%$ of them had an increase in BMI that shifted them to a higher BMI category and the other $7.7 \%$ adults moved to a lower BMI category due to weight loss. There were $10.1 \%$ and $4.7 \%$ adults who developed overweight and obesity between the 2011-2012 and 2015-2016 surveys, respectively. The 4-year-incidence of overweight was higher in men, whereas women had a higher incidence of obesity.

About $50.0 \%$ of the adults in the follow-up group maintained a stable weight (weight loss or gain $\leq 5.0 \%$ ), while $14.5 \%$ of adults lost $>5.0 \%$ of their baseline weight, and $35.5 \%$ had a weight gain of $>5.0 \%$ (Table 2 ). Weight gain was more apparent in women, adults in younger age group, those with higher educational attainment and reduced household income. The proportion of individuals with weight gain of $>5.0 \%$ in women, adults aged 18-28 years old and adults with secondary/tertiary education were $38.1 \%, 48.8 \%$ and $45.2 \%$, respectively. Across the baseline BMI categories, the proportion of adults with weight gain of $>5.0 \%$ was highest in the category of normal weight, followed by those who were overweight.

\section{DISCUSSION}

The present study found that overweight and obesity are important health problems prevalent among the Orang Asli adults living in this forest reserve area, as more than one-third were either overweight or obese. The study also showed that over the period of the follow-up, about $15.0 \%$ of these Orang Asli adults developed overweight and obesity. An earlier study of 16-35-yearold multi-ethnic persons in Malaysia showed that the Orang Asli had the highest prevalence of overweight and obesity (Pell et al., 2016). Our study has shown that the problem of overweight 


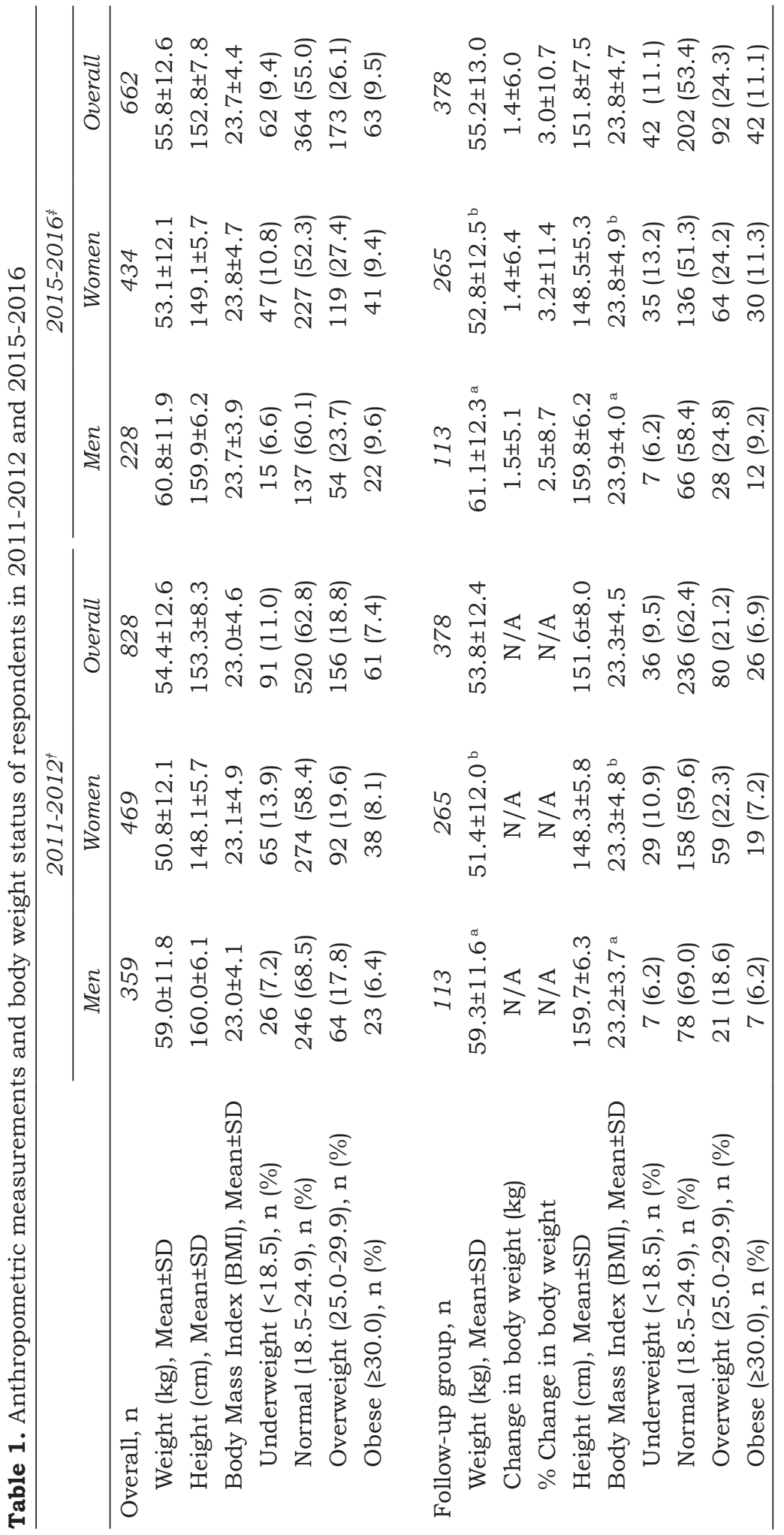




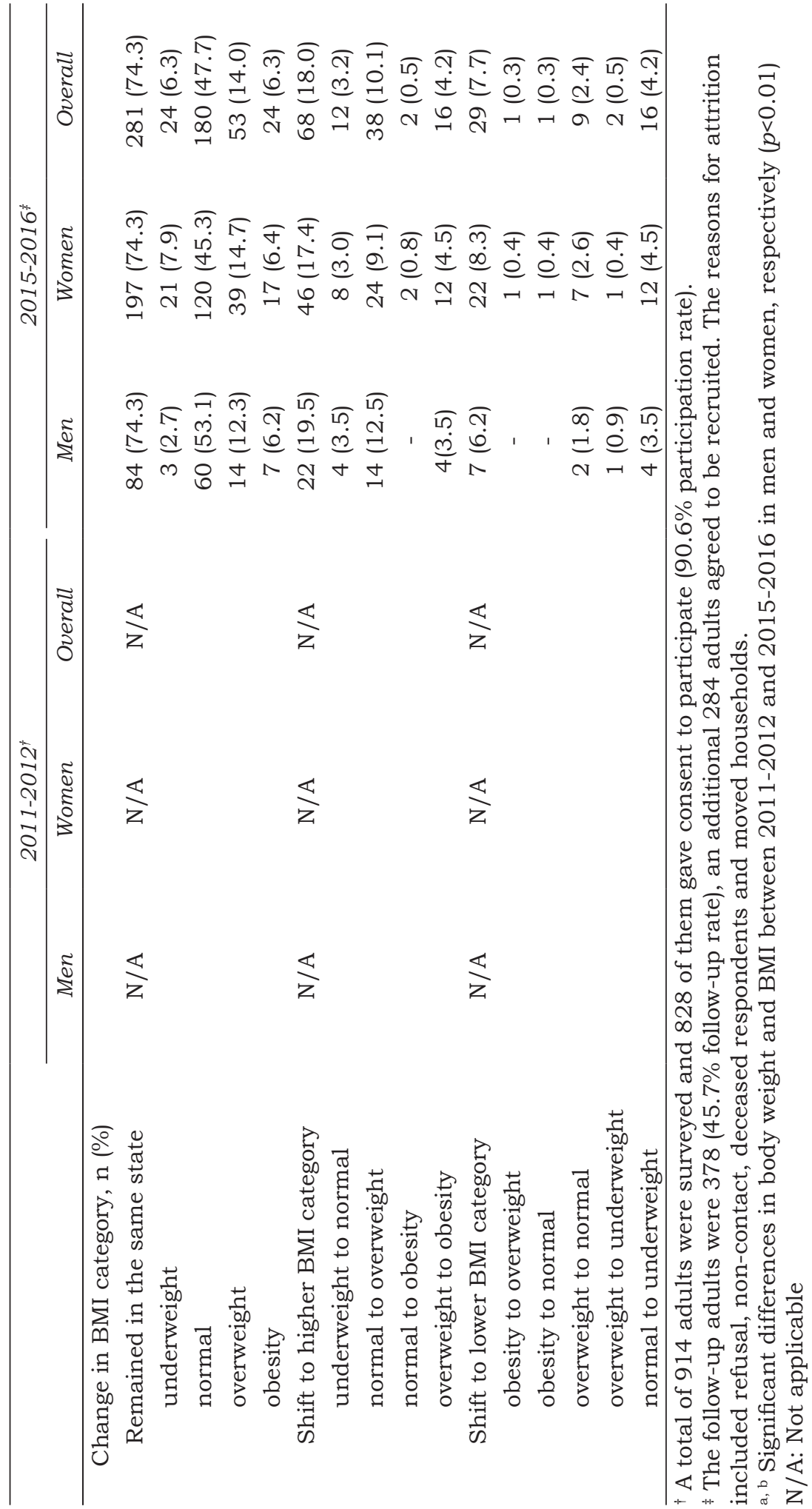




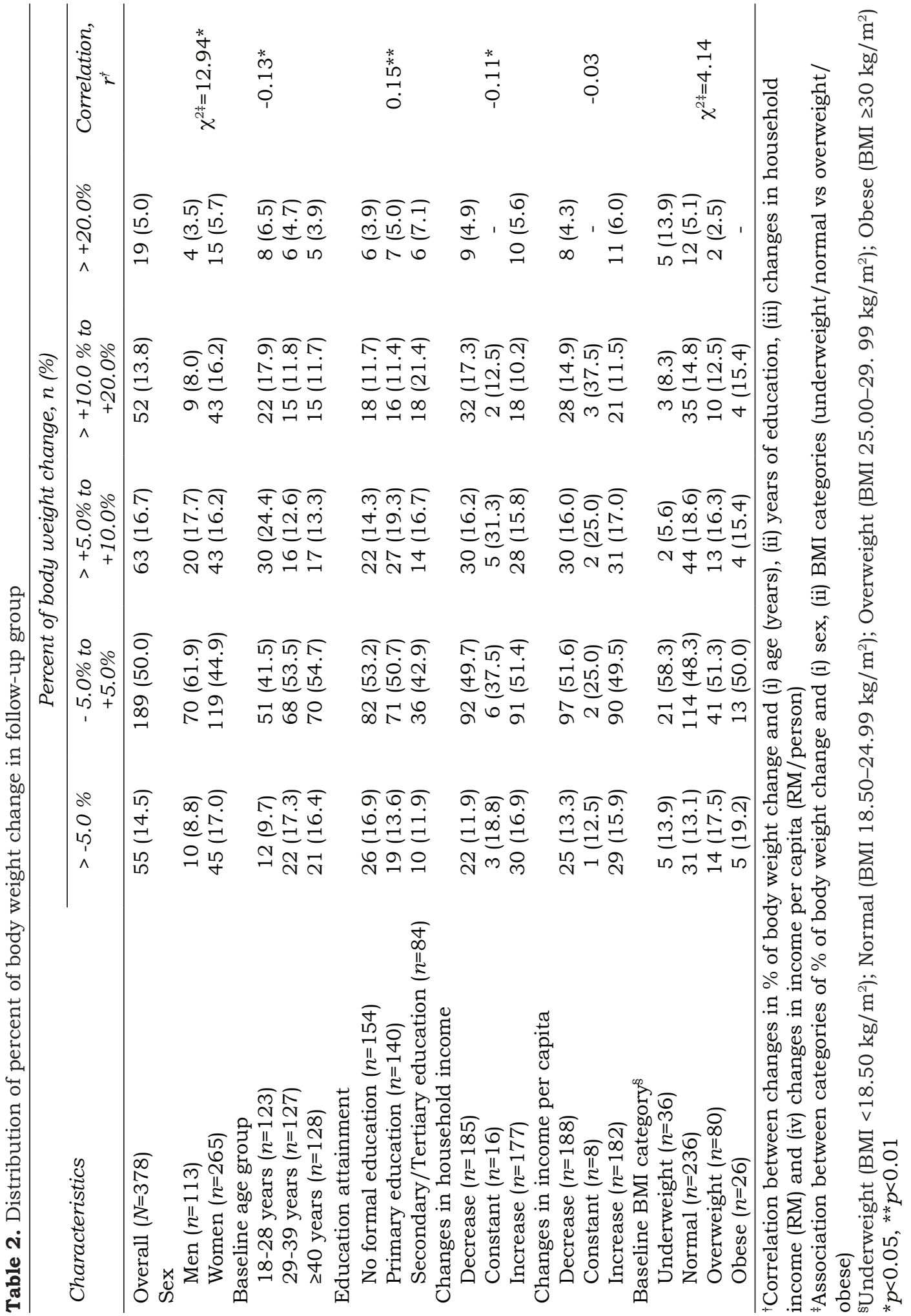


and obesity is growing in the Orang Asli population. It is a health issues that should be addressed.

The higher prevalence of overweight (>30.0\%) and obesity (20.0\%-45.0\%) has been observed in other indigenous groups in developed countries $(\mathrm{Ng}$, Corey \& Young, 2011; Hopkins et al., 2015; Thurber et al., 2018) and other developing countries such as Brazil (Oliveira et al., 2015). Indigenous obesity rates vary geographically. The lowest rates of overweight and obesity were found among those living in very remote areas (Australian Institute of Health and Welfare, 2014). This is probably because indigenous peoples living in such areas are more likely to consume traditional foods that are relatively high in nutrients, as reported by previous studies (Ghosh-Jerath et al., 2016; Ferguson et al., 2017). In Peninsular Malaysia, the proportion of Orang Asli living in urban areas has increased. The average percentage of Orang Asli in the urban areas has increased from $1.6 \%$ in 1970 to $>10.0 \%$ since year 2000 (Tuan Pah Rokiah, Devamany \& Asan, 2017). It is unclear whether the change in living environment (e.g. lack of access to forest and close proximity to markets) has led to a decrease in traditional food intake. Assessing the dependency on traditional and market foods over time of Orang Asli living in different locations may help to explain the change in overweight and obesity prevalence in this population.

The present study did not examine the impact of environmental factors on weight gain. However, the findings of this study indicated that sociodemographic factors may influence weight gain through their effects on energy intake and energy expenditure. Previous studies have indicated that adults from the lower socioeconomic strata had an increased risk of weight gain (Loman et al., 2013; Bhurosy \& Jeewon, 2014; Herzog et al., 2016). Findings of this study showed that income was negatively associated with weight gain among Orang Asli adults living in similar neighbourhoods. A majority of Orang Asli adults in this reserve area were rubber tappers (data not shown). Rather than the reliance on subsistence farming, they were more likely to purchase food from the market. Hence, income could greatly determine the food choices of the adults in the present study. When household income decreases and family budget for food shrinks, food choice tends to shift toward cheaper but more energydense foods. It could eventually result in excess calorie intake and weight gain. As shown in this study, Orang Asli adults with lower household income, had a greater percentage of weight gain. An earlier study among Orang Asli women also found that household income was negatively associated with household food security, while household food insecurity was significantly associated with a poorer diet quality and higher BMI (Chong, Geeta \& Norhasmah, 2018).

The present study showed that Orang Asli individuals with higher educational attainment had a greater percentage of weight gain. For individuals with lower education, they are more likely to assume highly demanding physical jobs as compared to their counterparts with higher education. Orang Asli adults, who were with higher education, were less likely to perform labour-intensive work and more likely to have less energy expenditure. Hence, they were at greater risk of weight gain. This study showed that younger aged Orang Asli had a greater weight gain, where about one-fourth of adults in the youngest cohort gained $>10.0 \%$ of weight in a period of four years. It was found that younger aged Orang Asli adults had a lower physical activity as compared to those with older age (data not shown). For example, active transport such as walking was lower among the younger 
Orang Asli adults. It has been reported that BMI increases sharply during the transition from adolescence to young adulthood (Lee et al., 2011) and weight gain during early to middle adulthood was significantly associated with an increased risk of chronic diseases (Zheng et al., 2017). To reduce the cost and disease burden associated with obesity, the prevention of overweight obesity in young adults should be prioritized (Dietz, 2017).

This study had some limitations. Some of the Orang Asli adults were highly mobile and efforts were made to address the problem. These included repeated household visits to track the participants as well as working with the community to explore how participants are commonly identified. Another limitation was that there are socioeconomic status indicators identified in the literature such as social class and wealth/assets that were not included in the present study. As with any kind of the selfreported data such as that on income, there is a risk of recall bias.

Despite these limitations, the strength of this study is the reporting of overweight and obesity prevalence at different time points and the changes in weight and BMI among Orang Asli adults over time. It is useful to increase the pool of available health-related information in Orang Asli population and to draw a greater attention to the increased risk of overweight and obesity in this population and its known attendant health risks.

\section{CONCLUSION}

This is one of the few studies that has reported the rising prevalence of overweight and obesity as well as the change in body weight in Orang Asli adults. Future studies that investigate the associations between the change in body weight and adverse health effects in Orang Asli population are warranted.
Health programmes on the prevention of excess weight gain, particular in younger and normal weight adults who appear to have greater weight gain, are needed. Furthermore, overweight and obese Orang Asli adults should also be monitored closely for the risk factors of chronic diseases and their complications.

\section{Acknowledgement}

This project was funded by the Fundamental Research Grant Scheme (FRGS), Ministry of Higher Education. The authors thank the data collection team members and all participants in the study.

\section{Authors' contributions}

CEY, conducted the study, undertook data analysis and interpretation, and prepared the draft of the manuscript; ZMS, participated in the conceptualisation of the study, its design, data interpretation, manuscript preparation and finalisation; NS and GA, reviewed the manuscript.

\section{Conflict of interest}

The authors declare no conflict of interest.

\section{References}

Australian Institute of Health and Welfare (2014). Australia's health 2014. Australia's health series no. 14. Cat. no. AUS 178. AIHW, Canberra.

Bhurosy T \& Jeewon R (2014). Overweight and obesity epidemic in developing countries: a problem with diet, physical activity, or socioeconomic status? The Scientific World Journal 2014:964236.

Chong SP, Geeta A \& Norhasmah S (2018). Household food insecurity, diet quality, and weight status among indigenous women (Mah Meri) in Peninsular Malaysia. Nutr Res and Pract 12(2):135-142.

Chua EY, Zalilah MS, Haemamalar K, Norhasmah S \& Geeta A (2017). Obesity indices predict hypertension among indigenous adults in Krau Wildlife Reserve, Peninsular Malaysia. J Health Popul Nutr 36(1):24.

Cui Z, Truesdale KP, Bradshaw PT, Cai J \& Stevens J (2015). Three-year weight change and cardiometabolic risk factors in obese and normal weight adults who are metabolically healthy: the atherosclerosis risk in communities study. Int J Obes (Lond) 39(8):1203-1208. 
Dietz WH (2017). Obesity and excessive weight gain in young adults: new targets for prevention. JAMA 318(3):241-242.

Espinosa De Ycaza AE, Donegan D \& Jensen MD (2018). Long-term metabolic risk for the metabolically healthy overweight/obese phenotype. Int J Obes (Lond) 42(3):302-309.

Ferguson M, Brown C, Georga C, Miles E, Wilson A \& Brimblecombe J (2017). Traditional food availability and consumption in remote Aboriginal communities in the Northern Territory, Australia. Aust $N Z J$ Public Health 41:294-298.

Geik OP, Sedek R \& Awang AF (2016). Malnutrition and associated factors of Aboriginal preschoolers in Gua Musang, Kelantan, Malaysia. Pakistan J Nutr 15(2):133-139.

Ghosh-Jerath S, Singh A, Magsumbol MS, Lyngdoh T, Kamboj P \& Goldberg G (2016). Contribution of indigenous foods towards nutrient intakes and nutritional status of women in the Santhal tribal community of Jharkhand, India. Public Health Nutr 19(12):2256-2267.

GBD 2015 Obesity Collaborators (2017). Health effects of overweight and obesity in 195 countries over 25 years. $N$ Engl J Med 377(1):13-27.

Herzog B, Lacruz ME, Haerting J, Hartwig S, Tiller D, Medenwald D, Vogt S, Thorand B, Holle R, Bachlechner U, Boeing H, Merz B, Nothlings $\mathrm{U}$, Schlesinger S, Schipf S, Ittermann T, Aumann N, Schienkiewitz A, Haftenberger M, Greiser KH, Neamat-Allah J, Katzke V \& Kluttig A (2016). Socioeconomic status and anthropometric changes-A meta-analytic approach from seven German cohorts. Obesity (Silver Spring) 24(3):710-718.

Hopkins SE, Austin MA, Metzger JS, Koller KR, Umans JG, Kaufmann C, Wolfe AW, Howard BV \& Boyer BB (2015). Sex differences in obesity prevalence and cardiometabolic factors among Western Alaska Native people. Nutr Metab Cardiovasc Dis 25(3):312-318.

Lee H, Lee D, Guo G \& Harris KM (2011). Trends in body mass index in adolescence and young adulthood in the United States: 1959-2002. J Adolesc Health 49(6):601-608.

Loman T, Lallukka T, Laaksonen M, Rahkonen O \& Lahelma E (2013). Multiple socioeconomic determinants of weight gain: the Helsinki Health Study. BMC Public Health 13:259.

NCD-RisC (2016). Trends in adult body-mass index in 200 countries from 1975 to 2014: A pooled analysis of 1698 population-based measurement studies with $19 \cdot 2$ million participants. Lancet 387(10026): 1377-1396.
Ng C, Corey PN \& Young TK (2011). Socioeconomic patterns of obesity among Aboriginal and nonAboriginal Canadians. Can $J$ Public Health 102:264-268.

Oliveira GF, Oliveira TR, Ikejiri AT, Galvao TF, Silva MT \& Pereira MG (2015). Prevalence of obesity and overweight in an indigenous population in Central Brazil: A population-based crosssectional study. Obes Facts 8(5):302-310.

Pell C, Allotey P, Evans N, Hardon A, Imelda JD, Soyiri I, Reidpath DD \& SEACO Team (2016). Coming of age, becoming obese: a cross sectional analysis of obesity among adolescents and young adults in Malaysia. BMC Public Health 16:1082.

Phipps ME, Chan KK, Naidu R, Mohamad NW, Hoh BP, Quek KF, Ahmad B, Harnida SM, Zain AZ \& Kadir KA (2015). Cardio-metabolic health risks in indigenous populations of Southeast Asia and the influence of urbanization. BMC Public Health 15:47.

Siti Fatihah M, Gan WY, Norhasmah S \& Zalilah MS (2018). Factors associated with stunting among Orang Asli preschool children in Negeri Sembilan, Malaysia. Mal J Nutr 24(2):215-226.

Thurber KA, Joshy G, Korda R, Eades SJ, Wade V, Bambrick H, Liu B \& Banks E (2018). Obesity and its association with sociodemographic factors, health behaviours and health status among Aboriginal and non-Aboriginal adults in New South Wales, Australia. J Epidemiol Community Health 72(6):491-498.

Tuan Pah Rokiah SH, Devamany SK \& Asan Ali $\mathrm{GH}$ (2017). Distribution and demography of the Orang Asli in Malaysia. Int $J$ Humanities \& Social Science Invention 6(1):40-45.

Wong CY, Zalilah MS, Chua EY, Norhasmah S, Chin YS \& Siti Nur'Asyura A (2015). Doubleburden of malnutrition among the indigenous peoples (Orang Asli) of Peninsular Malaysia. BMC Public Health 15:680.

Yiengprugsawan V, Rimpeekool W, Papier K, Banwell C, Seubsman SA \& Sleigh AC (2017). Relationship between 8-year weight change, body size, and health in a large cohort of adults in Thailand. J Epidemiol 27(10):499-502.

Zheng Y, Manson JE, Yuan C, Liang MH, Grodstein F, Stampfer MJ, Willett WC \& Hu FB (2017). Associations of weight gain from early to middle adulthood with major health outcomes later in life. JAMA 318(3):255-269. 